\title{
Estimation of Survival Rates in Patients with Lung Cancer in West Azerbaijan, the Northwest of Iran
}

\author{
Malek Abazari ${ }^{1}$, Mahdia Gholamnejad ${ }^{2}$, Ghodratollah Roshanaei ${ }^{3}$, Reza \\ Abazari $^{4}$, Yousef Roosta ${ }^{5}$, Hossein Mahjub ${ }^{6 *}$
}

\begin{abstract}
Background: Lung cancer is a fatal malignancy with high mortality and short survival time. The aim of this study was to estimate survival rates of Iranian patients with lung cancer and its associate predictive factors. Materials and Methods: The study was conducted on 355 patients admitted to hospitals of West Azerbaijan in the year 2007. The patients were followed up by phone calls until the end of June 2014. The survival rate was estimated using the Kaplan-Meier method and log-rank test for comparison. The Cox's proportional hazard model was used to investigate the effect of various variables on patient survival time, including age, sex, Eastern Cooperative Oncology Group (ECOG) performance, smoking status, tumor type, tumor stage, treatment, metastasis, and blood hemoglobin concentration. Results: Of the 355 patients under study, 240 died and 115 were censored. The mean and median survival time of patients was 13 and 4.8 months, respectively. According to the results of Kaplan-Meier method, 1, 2, and 3 years survival rates were 39\%, 18\%, and $0.07 \%$, respectively. Based on Cox regression analysis, the risk of death was associated with ECOG group V (1.83,95\% CI: 1 Conclusions: The survival time of the patients with lung cancer is very short. While early diagnosis may improve the life expectancy effective treatment is not available.
\end{abstract}

Keywords: Lung neoplasm - cox model - survival - Iran

Asian Pac J Cancer Prev, 16 (9), 3923-3926

\section{Introduction}

Among all diseases, a majority of human effort has been allocated to fight with cancer (Amirimoghadam, 2012). Cancer is one of the major causes of morbidity, mortality and disability worldwide (Haghshenas et al., 2013). Lung cancer is a very common disease with an increasing trend (Bollschweiler et al., 2002). In Iran, after cardiovascular diseases and accidents, cancer is the third leading cause of death (Mousavi et al., 2009). Lung cancer is an important and fatal cancer a five-year survival rate of only $13 \%$ after the time of diagnosis (OZLU and BULBUL, 2005; Haraguchi et al., 2012). Cancers in Iran as a whole imposed 662.2 Disability Adjusted Life Years (DALY) per hundred thousand people and after the gastric cancer, the lung cancer is in the second important fatal cancerwith 56.3 DALY (Bollschweiler et al., 2002).

According to classification of the America Cancer Society, there are two types of lung cancer: (a) small cell carcinoma (SCC) and (b) non-small cell carcinoma (NSCC), there are many forms of this cancer. This type of lung cancer is defined according to the type of cells in the lung tissue (Macdonald et al., 2004). The three main subtypes of NSCC are adenocarcinoma, squamous-cell carcinoma and large-cell carcinoma (Horn et al., 2012).

SCC involves dense neurosecretory granules (Rosti et al., 2006). Most cases arise in the larger airways (primary and secondary bronchi) (Collins et al., 2007). SCC is the most common type of lung cancer and has rapid growth and metastasis rate, and spreads to other organs easily. About $67 \%$ of cases have metastatic disease at time of diagnosis. This type of lung cancer is strongly associated with smoking (Horn et al., 2012). NSCC is often treated with surgery, while SCC usually responds better to chemotherapy and radiotherapy (Chapman et al., 2009).

Lung cancer is one of the main causes of death among known cancers and has the highest mortality rates compared to the cancers of breast, prostate and other multiple cancers (a person that getting more than one type of cancer) (Zahir and Mirtalebi, 2012). Unfortunately, it takes a very long time until the lung cancer symptoms become evident. Therefore, in most cases the disease is diagnosed in advanced stages (Fauci, 2008; Silvestri et al., 2009).

${ }^{1}$ Department of Epidemiology and Biostatistics, ${ }^{3}$ Modeling of Noncommunicable Diseases Research Center, ${ }^{6}$ Research Center for Health Sciences, School of Public Health, Hamadan University of Medical Sciences, Hamadan, ${ }^{2}$ Pulmonology Department, ${ }^{5}$ Internal Medicine Department, Urmia University of Medical Sciences, Urmia, ${ }^{4}$ Young Researchers and Elite Club, Ardabil Branch, Islamic Azad University, Ardabil,Iran *For correspondence: mahjub@umsha.ac.ir 
Survival rate of patients with any type of cancer is one of the most important indicators in disease control and evaluation of treatment methods (Klein, 2005). Taghipour et al reported a mean survival time of 8.5 months for patients with lung cancer. They reported that only $25 \%$ of patients had survived more than one year (Zahir and Mirtalebi, 2012). Drech Gross et al reported a median survival time of 6.5 months for patients with lung cancer and a one-year survival rate of $30 \%$ (Grose et al., 2014). Santro et al obtained median survival time of 15.7 months. They estimated median survival time of patients 14.9 and 22.1 months for smokers and non-smokers, respectively (Santoro et al., 2011). Mathew et al reporteda median survival time of 15.2 months with 5-years survival rate of $11 \%$ in patients with lung cancer (Schabath et al., 2014). Goksel et al also reporteda median survival of 16.9 months with 5-year survival rate of 9\% (Goksel et al., 2013).

West Azerbaijan province is in the northwest of Iran. Until now, no comprehensive study has conducted to examine the lung cancer survival rate and its associated risk factors. This is the first study conducted in this province to estimate survival rate of patients with lung cancer and to determine its associated predictive factors.

\section{Materials and Methods}

In this retrospective cohort study, demographic and biological information of all patients with lung cancer admitted to university hospitals of West Azerbaijan province was obtained from 2007 to 2014. Demographic variables included age at time of diagnosis, and gender. Biological variables includedEastern Cooperative Oncology Group (ECOG) performance, smoking, tumor type, tumor stage, metastasis, and blood hemoglobin concentration. The patients were followed by the June 2014 and their information obtained from medical records and through phone calls and home visits. The patients who lost to follow up or diedfor reasons other than lung cancer or was alive at the end of the study were considered as censored. The duration of survival time was measured in months from the time of diagnosis until the end of the study period. The event of interest was death from lung cancer.

The data were analyzed using Stata and R software. Survival rates were estimated by Kaplan-Meier method and compared by Log-rank test to assess the effect of various variables on the patients' survival time. In addition,simple and multiple Cox's regression analyses were performed. The assumption of hazard proportionality was checked by the Schenofeld residual test. The assumption was not rejected for any variable. Significance level for statistical tests was 0.05 .

\section{Results}

Of the 355 patients under study, 240 died and 115 were censored. About $72.1 \%$ of the patients (256 cases) were males and $27.9 \%$ (99 cases) were females (male to female ratio was 2.6). The mean age at time of diagnosis was $63.5 \pm 13.5$ (ranged from 11 to 91 years). The mean age at time of diagnosis for men and women was $65.0 \pm 12.4$ and
$59.4 \pm 15.5$ years, respectively $(\mathrm{p}=0.002)$. The mean and median survival time of patients was 13 and 4.8 months, respectively. The mean and median survival time for men was 12.5 and 8.1 months and that of women was13.9 10.1 months, respectively. The Log-rank test did not show any significant difference between the survival time in men and women $(\mathrm{p}=0.350)$.

According to the results of Kaplan-Meier method, 1, 2 , and 3 years survival rate of patients was $39 \%, 18 \%$, and $0.07 \%$, respectively (Figure 1). One-year survival rate was $38 \%$ for men and $41 \%$ for women, which log-rank test did

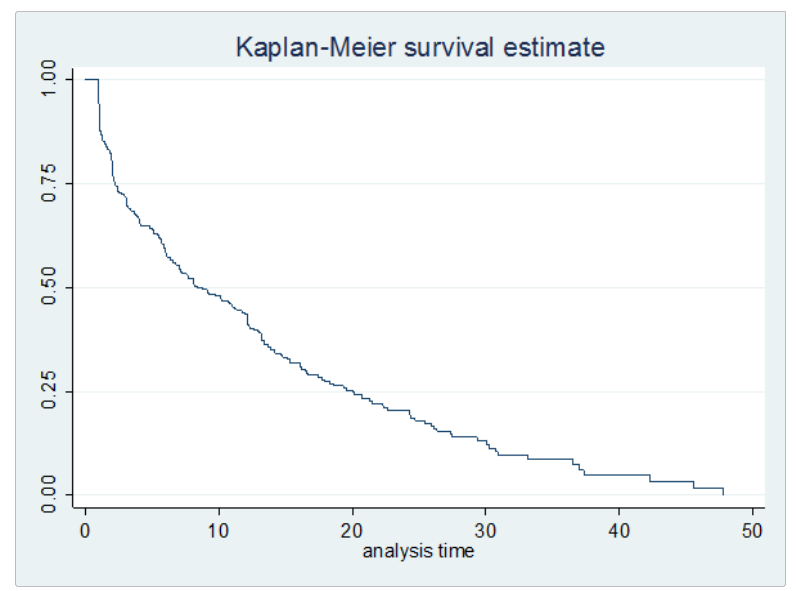

Figure 1. Kaplan-Meier Survival Rate Estimation for Patients with Lung Cancer

Table 1. Demographic and Clinical Characteristics of Patients with lung Cancer

\begin{tabular}{|c|c|}
\hline Variables & Number $(\%)$ \\
\hline \multicolumn{2}{|l|}{ Sex } \\
\hline Male & $256(72.1)$ \\
\hline Female & 99 (27.9) \\
\hline \multicolumn{2}{|l|}{ Age (yr) } \\
\hline$<60$ & $137(39.5)$ \\
\hline $60-75$ & $145(41.8)$ \\
\hline$>75$ & $65(18.7)$ \\
\hline \multicolumn{2}{|c|}{ Eastern Cooperative Oncology Group } \\
\hline $\mathrm{I}, \mathrm{II}$ & $80(22.8)$ \\
\hline III & 161(45.9) \\
\hline $\mathrm{V}$ & $110(31.3)$ \\
\hline \multicolumn{2}{|l|}{ Smoking Status } \\
\hline Smoker & $245(69.2)$ \\
\hline Non-smoker & $109(30.8)$ \\
\hline \multicolumn{2}{|l|}{ Tumor type } \\
\hline Adenocarcinoma & $80(26.6)$ \\
\hline SCC & $132(43.9)$ \\
\hline Lung Cell & $5(1.7)$ \\
\hline Carcinoid \& Other & $58(19.3)$ \\
\hline Extensive & $22(7.3)$ \\
\hline Limited & $4(1.3)$ \\
\hline \multicolumn{2}{|l|}{ Tumor stage } \\
\hline I & $3(1)$ \\
\hline II & $33(10.5)$ \\
\hline III & $64(20.4)$ \\
\hline IV & $213(68.1)$ \\
\hline \multicolumn{2}{|l|}{ Treatment } \\
\hline Received & $186(65)$ \\
\hline Not-received & $101(35)$ \\
\hline \multicolumn{2}{|l|}{ Metastasis } \\
\hline Yes & $191(53.8)$ \\
\hline No & $164(46.2)$ \\
\hline
\end{tabular}


Table 2. The results of univariate and multiple Cox regression model

\begin{tabular}{|c|c|c|c|}
\hline Variables & $\begin{array}{c}\text { HR(95\% CI) } \\
\text { Unadjusted }\end{array}$ & Adjusted & $\begin{array}{l}\text { Median Survival time } \\
\qquad(95 \% \mathrm{CI})\end{array}$ \\
\hline \multicolumn{4}{|l|}{ Sex } \\
\hline Female & 1 & Not included in the model & $10.1(6.1,14.1)$ \\
\hline Male & $1.14(0.85,1.54)$ & & $8.1(5.3,10.9)$ \\
\hline \multicolumn{4}{|l|}{ Age (yr) } \\
\hline$<60$ & 1 & 1 & $12.2(9.5,15)$ \\
\hline $60-75$ & $1.37(1.02,1.83)$ & $1.11(0.08,1.56)$ & $8.3(4.3,12)$ \\
\hline $75>$ & $2.12(1.47,3.04)$ & $1.21(0.76,1.93)$ & $3.4(1.7,5.2)$ \\
\hline \multicolumn{4}{|c|}{ Eastern Cooperative Oncology Group } \\
\hline $\mathrm{I}, \mathrm{II}$ & 1 & 1 & $16(12,21.2)$ \\
\hline III & $1.51(1.05,2.17)$ & $1.37(0.88,2.12)$ & $10.8(7.7,5.2)$ \\
\hline $\mathrm{V}$ & $2.78(1.92,4.2)$ & $1.83(1.51,2.92)$ & $3.7(2,5.4)$ \\
\hline \multicolumn{4}{|l|}{ Smoking Status } \\
\hline Non-smoker & 1 & 1 & $13.2(11.5,14.9)$ \\
\hline Smoker & $1.62(1.22,2.15)$ & $2(1.4,2.83)$ & $6(3.9,8.2)$ \\
\hline \multicolumn{4}{|l|}{ Tumor type } \\
\hline NSCLC & 1 & & $10.7(8.4,13)$ \\
\hline SCLC & $1.04(0.66,1.66)$ & Not included in the model & $12.2(5,19.3)$ \\
\hline \multirow{2}{*}{\multicolumn{4}{|c|}{$\begin{array}{l}\text { Carcinoid } \\
\quad \text { Tumor stage }\end{array}$}} \\
\hline & & & \\
\hline I,II,III & 1 & 1 & $11(8,14)$ \\
\hline IV & $1.42(1.04,1.93)$ & $1.06(0.69,1.61)$ & $7(5,9.2)$ \\
\hline \multicolumn{4}{|l|}{ Treatment } \\
\hline Received & 1 & 1 & $12.2(10.5,13.9)$ \\
\hline Not-received & $2.58(1.94,3.42)$ & $2.2(1.56,3.8)$ & $2.1(1.3,3)$ \\
\hline \multicolumn{4}{|l|}{ Metastasis } \\
\hline No & 1 & 1 & $12.2(9.6,14.7)$ \\
\hline Yes & $1.57(1.21,2.04)$ & $1.28(0.87,1.9)$ & $5.8(4.4,7.3)$ \\
\hline
\end{tabular}

not showany significant difference $(\mathrm{p}=0.272)$.

Lung cancers based on histological classification are divided into three types of NSCC, SCC and carcinoid tumor. In this study, $71.8 \%$ of cases had NSCC, $9 \%$ had SCC and $19.3 \%$ had carcinoid tumor. The mean and standard deviation of blood hemoglobin was $11.9( \pm 2.2)$ $\mathrm{mg} / \mathrm{dl}$ for men and was $11.2 \pm 1.9 \mathrm{mg} / \mathrm{dl}$ for women. Other characteristics of the patients are given in Table 1 .

The results of univariate Cox regression showed that male patients, whose blood hemoglobin level was less than $14 \mathrm{mg} / \mathrm{dl}$ had a higher survival rate compared to male subjects with a blood hemoglobin level more than $14 \mathrm{md} /$ $\mathrm{dl}(\mathrm{p}=0.021, \mathrm{HR}=1.44)$. This variable was not significant for females $(\mathrm{p}=0.507, \mathrm{HR}=1.23)$.

To evaluate the effect of variables on survival time, unadjusted univariate Cox's regression was used. The results showed that age at diagnosis time, smoking status, tumor type, treatment, and metastasis had a significant effect on the survival time (Table 2). In addition, multiple Cox regression was used to estimate the adjusted effects of potential risk factors on survival time. In multiple Cox regression the ECOG performance, smoking status and treatment was significantly associated with survival time of patients with lung cancer. Unlike univariate regression, the adjusted association between lung cancer and age at the time diagnosis, tumor stage, and metastasis was not statistically significant in multiple regression analysis (Table 2).

\section{Discussion}

The results of this study indicated that age at the time of diagnosis, ECOG performance, smoking status, stage group, treatment, and metastasis had a significant effect on the patients' survival probability.

Based on our results, the mean age at the time diagnosis was consistent with to results of other studies conducted in Iran and other countries (Arrieta et al., 2012; Zahir and Mirtalebi, 2012). Although sex is one of the effective factors on survival time, in the current study, the sex was not significantly related to survival time as was reported by Zahir Mirtalebi et al. (2012).However, some studies have indicated that survival time in women is more than in men (Battafarano et al., 2002; Puri et al., 2010).

In this study, we indicated a significant reverse association between age at diagnosis and survival time, so that the survival time decreased with age. The hazard ratio for patients older than 75 years was more than two fold higher than patients aged 60 years or younger. Similar studies confirm such a finding (Puri et al., 2010; Zahir and Mirtalebi, 2012).

According to our findings, there was a significant association between ECOG performance and survival time. The patients in group $\mathrm{V}$ had the lowest survival time and followed by patients in group III.

In the current study, the most common type of lung cancer was SCC and adenocarcinomaand carcinoid were in the second and third most common lung cancers. There was no significant association between tumor type and survival rate. This finding was consistent with the results of similar to other studies conducted in Iran (Zahir and Mirtalebi, 2012; Hajmanoochehri et al., 2014) but inconsistent with the results of studies carried out in other countries. Some studies in other countries have reported 


\section{Malek Abazari et al}

adenocarcinoma as the most common type of lung cancer (Haraguchi et al., 2012; Jiang et al., 2012).

There was a significant association betweentumor stage and survival time. Approximately, $68 \%$ of patients were in the stage IV. Patients with tumor stage IV had a hazard ratio of 1.4 compared to those with tumor stages I, II, or III.The results of study performed by Kawaguchi et Al confirmed our results (Kawaguchi et al., 2010).

Subjects who received chemotherapy, radiotherapy, or underwent surgery had longer survival time than those subjects who did not receive any treatment. This finding was consistent with the results of similar studies (Berghmans et al., 2005; Zahir and Mirtalebi, 2012).

Mitsudomietal(Mitsudomi et al., 2010) and Kawaguchi etal (Kawaguchi et al., 2010) reported that smoking had a significant effect onthe survival time. It should be mentioned that from 96 non-smoker patients, 75 patients were with stage IV tumors, and only 21 patients were in other tumor stages.

Metastasis was another factor that had a significant effecton the survival time. Patients who had metastases had a median survival time of 5.8 months while the median survival time of the patients without metastases was 12.2 months.

In conclusion, the survival time of the patients with lung cancer is very short while early diagnosis of disease may improve the life expectancy in patients with lung cancer although effective treatment is not available for this cancer.

\section{Acknowledgements}

We would like to thank the Vice-chancellor for Education as well as Vice-chancellor for Research and Technology of Hamadan University of Medical Sciences for financial support of this study.

\section{References}

Arrieta O, Nunez-Valencia C, Reynoso-Erazo L, et al (2012). Health-related quality of life in patients with lung cancer: validation of the Mexican-Spanish version and association with prognosis of the EORTC QLQ-LC13 questionnaire. Lung Cancer. 77, 205-11.

Battafarano RJ, Piccirillo JF, Meyers BF, et al (2002). Impact of comorbidity on survival after surgical resection in patients with stage I non-small cell lung cancer. J Thoracic Cardiovascular Surg. 123, 280-7.

Berghmans T, Paesmans M, Meert AP, et al (2005). Survival improvement in resectable non-small cell lung cancer with (neo)adjuvant chemotherapy: results of a meta-analysis of the literature. Lung Cancer, 49, 13-23.

Bollschweiler E, Wolfgarten E, Nowroth T, et al (2002). Vitamin intake and risk of subtypes of esophageal cancer in Germany. J Cancer Res Clin Oncol. 128, 575-80.

Fauci AS (2008). Harrison's Principles of Internal Medicine: McGraw-Hill Medical New York.

Goksel T, Eser S, Guclu SZ, et al (2013). Prognostic factors affecting survival in cases with lung cancer [A lung cancer mapping project in Turkey (LCMPT)]. Eur Res J, 42, 2920.

Grose D, Devereux G, Brown L, et al (2014). Simple and objective prediction of survival in patients with lung cancer: staging the host systemic inflammatory response. Lung
Cancer International, 6, 500-9

Haghshenas M, Golini-Moghaddam T, Rafiei A, et al (2013). Prevalence and type distribution of high-risk human papillomavirus in patients with cervical cancer: a populationbased study. Infect Agent Cancer, 8, 20.

Hajmanoochehri F, Mohammadi N, Zohal MA, Sodagar A, Ebtehaj M (2014). Epidemiological and clinicopathological characteristics of lung cancer in a teaching hospital in iran. Asian Pac J Cancer Prev, 15, 2495.

Haraguchi S, Koizumi K, Mikami I, et al (2012). Clinicopathological characteristics and prognosis of non-small cell lung cancer patients, associated with a family history of lung cancer. Int J Med Sciences, 9, 68.

Jiang X, de Groh M, Liu S, Liang H, Morrison H (2012). Rising incidence of adenocarcinoma of the lung in Canada. Lung Cancer, 78, 16-22.

Kawaguchi T, Takada M, Kubo A, et al (2010). Gender, histology, and time of diagnosis are important factors for prognosis: analysis of 1499 never- smokers with advanced non-small cell lung cancer in Japan. J Thoracic Oncol, 5, 1011-7.

Klein M (2005). Survival analysis: a self-learning text: Springer.

Macdonald F, Ford C, Casson A (2004). Molecular biology of cancer: Taylor and Francis.

Mitsudomi T, Morita S, Yatabe Y, et al (2010). Gefitinib versus cisplatin plus docetaxel in patients with non-small-cell lung cancer harbouring mutations of the epidermal growth factor receptor (WJTOG3405): an open label, randomised phase 3 trial. lancet oncol, 11, 121-8.

Mousavi SM, Gouya MM, Ramazani R, Davanlou M, Hajsadeghi $\mathrm{N}$, Seddighi Z (2009). Cancer incidence and mortality in Iran. Ann Oncol, 20, 556-63.

Ozlu T, Bulbul Y (2005). Smoking and lung cancer. Tuberkuloz ve Toraks Dergisi, 53, 200-9.

Puri V, Garg N, Engelhardt EE, Kreisel D, Crabtree TD, Meyers $\mathrm{BF}$, et al (2010). Tumor location is not an independent prognostic factor in early stage non-small cell lung cancer. Ann Thorac Surg, 89, 1053-9.

Santoro IL, Ramos RP, Franceschini J, Jamnik S, Fernandes ALG (2011). Non-small cell lung cancer in never smokers: a clinical entity to be identified. Clinics, 66, 1873-7.

Schabath MB, Nguyen A, Wilson P, Sommerer KR, Thompson ZJ, Chiappori AA (2014). Temporal trends from 1986 to 2008 in overall survival of small cell lung cancer patients. Lung Cancer, 86, 14-21.

Silvestri GA, Alberg AJ, Ravenel J (2009). The changing epidemiology of lung cancer with a focus on screening. BMJ: British Medical Journal.451-4.

Zahir ST, Mirtalebi M (2012). Survival of patients with lung cancer, Yazd, Iran. Asian Pac J Cancer Prev, 13, 4387-91. 